\title{
Zoledronic Acid and the Mevalonate Pathway: An Opportunity to Overcome Resistance in Hormonal HER2 positive Breast Cancer
}

\author{
Susanne Crocamo*1 and Bruno Henrique Rala de Paula ${ }^{2}$ \\ ${ }^{1}$ Head of Oncology and Breast Cancer Research Unit, INCA, Brazil \\ ${ }^{2}$ Professor of Oncolgoy, University of Vassouras, Brazil \\ *Corresponding author: Susanne Crocamo, Professor of Oncolgoy, University of Vassouras, Brazil. \\ To Cite This Article: Susanne Crocamo. Zoledronic Acid and the Mevalonate Pathway: An Opportunity to Overcome Resistance in Hormonal \\ HER2 positive Breast Cancer. Am J Biomed Sci \& Res. 2019 - 2(6). AJBSR.MS.ID.000618. DOI: 10.34297/AJBSR.2019.02.000618
}

Received: April 18, 2019 | Published: May 08, 2019

The Human Epidermal growth factor Receptor-type2 (HER2) positive breast characteristics and treatment

The HER2 positive breast cancer subtype exhibits a distinct behaviour from the others, usually accompanied with early relapse, including a higher percentage of brain metastasis [1]. Therefore, it remains a challenge in clinical practice [2]. On the other hand, anti-HER2 target therapy has dramatically changed the course of the disease [3]. In neoadjuvant, adjuvant and metastatic setting, the advent of trastuzumabe and pertuzumab, both monoclonal antibody which binds to HER2 receptor in different domains on tumoral cells inhibiting it progression synergistically with cytotoxic chemotherapy, has improved several endpoints such as pathological complete response rate, relapse-free, progressionfree and overall survival [4]. Beyond trastuzumab and pertuzumab combination, an antibody- drug conjugate (ADC) like trastuzumab emtansine (T-DM1) and an irreversible pan-HER tyrosine kinase inhibitor (TKI) such as neratinib meliorated the previous endpoints $[5,6]$. However, many patients still develop disease recurrence or progressive disease and die.

The current effort from scientists and clinicians is improve the results of anti-HER therapy and mainly it's resistance [7]. There is a bidirectional crosstalk between HER2 and estrogen pathway [8]. Anti-HER2 targeting can up-regulate estrogen pathways and additionally estrogen pathway activation can reduce antiHER2 activity [9]. Differences in responses are expected to occur depending on the positivity of hormonal receptors, justifying humbled performances of HR-positive subtype when compared to HR- negative in terms of pathological response rate in clinical trials as shown by Schedin 2018. Strategies to overcome resistance in HER2- positive breast cancer includes TKIs [10], and combinations of anti-HER2 therapy with other agents like immune checkpoint inhibitors [11], CDK4/6 inhibitors [12], and PI3K/AKT/mTOR inhibitors [13]. While the raise of cyclin inhibitors in pre-clinical models seems to be promising [14] and several studies are ongoing, other attempts has generally failed in demonstrating improvements such as standard therapy combination with hormonal agents in neoadjuvant setting [15].

Furthermore, absence of significant overall survival benefit and a humbled benefit if progression-free survival was reported in metastatic setting when hormonal agents are combined with antiHER2 requiring other strategies [16,17].

\section{Crosstalk's between HER2 and Mevalonate Pathway}

Pre-clinical evidence revealed the previously unknown crosstalk between the estrogen, HER2, Notch and the mevalonate pathway [18]. HER2 protein initiates a cascade of phosphorylation's when activated [19]. Then interaction between core promotion and maintaining cell survival pathways occurs [20], such as the mitogen-activated RAS-RAF-protein kinase (MAPK)/extracellular signal- regulated kinase (MEK)-ERK and the phosphoinositide 3-kinase (PI3K)-PTEN-AKT, as schematic shown by in the figure 1 from Goltsov et al 2018 paper [21].

Zoledronic Acid Combination and the Its Potential Benefits

Zoledronic acid (ZOL) is a bisphosphonate which promotes clinical benefits in breast cancer [22,23]. In preclinical scenario, it demonstrated apoptotic, anti- proliferation [24] and antiangiogenic effect [25], reduction of invasion and cell migration [26], immunogenic effect [27] and act synergistically with chemotherapy $[28,29]$. When the farnesyl pyrophosphate synthetize activity is inhibited by ZOL affecting the mevalonate metabolism, a GTPases proteins prenylation do not occurs, interfering with RAS activity, resulting in a potential anti-tumoral activity [30]. The Zo-NAnTax trial [31], is a proof of concept phase II study that explores this 
potential therapeutic benefit based on drug repositioning [32] from our group. HER2-positive locally advanced breast cancer patients were treated with four cycles of anthracycline/cyclophosphamide (AC) plus zoledronic acid (ZOL), followed by four cycles of docetaxel with trastuzumab plus ZOL (ACZOLx4 > THZOLx4) pre- operatively. The primary endpoint in this trial was pathologic complete response (pCR) and most relevantly the secondary molecular end-points might potentially translate this pre-clinical into clinical evidence. The study was finished however results are to be published.

\section{Conclusion}

HER2-positive breast cancer treatment is a challenge, however the crosstalk between the estrogen, HER2, Notch and the mevalonate pathways represents a window of opportunity to improve resistance in this subset of tumours.

\section{References}

1. Pondé, Noam (2018) Treatment of advanced HER2- positive breast cancer: 2018 and beyond. Cancer Treat Rev 67: 10-20.

2. Puglisi, Fabio (2016) Current challenges in HER2- positive breast cancer. Crit Rev Oncol Hematol 98: 211-221.

3. Harbeck, Nadia (2018) Advances in targeting HER2-positive breast cancer. Curr Opin Obstet Gynecol. 30(1): 55-59.

4. Thomssen, Christoph (2017) Dual HER2 Blockade. Breast Care (Basel) 12(5): 345-349.

5. Verma, Sunil (2012) Trastuzumab emtansine for HER2- positive advanced breast cancer. N Engl J Med 367(19): 1783-1791.

6. Chan, Arlene, Moy B, Iwata H, Harvey VJ, et al. (2016) Neratinib after trastuzumab-based adjuvant therapy in patients with HER2-positive breast cancer (ExteNET): a multicentre, randomised, double-blind, placebo- controlled, phase 3 trial. Lancet Oncol 17(3): 367- 377.

7. (2017) Breast cancer targeted therapy: successes and challenges. Lancet 389(10087): 2350.

8. Giuliano, Mario, Meghana V Trivedi, Rachel Schiff (2013) Bidirectional crosstalk between the estrogen receptor and human epidermal growth factor receptor 2 signaling pathways in breast cancer: molecular basis and clinical implications. Breast Care (Basel). 8(4): 256-262.

9. Schedin, Troy B, Virginia F Borges, Elena Shagisultanova (2018) Overcoming Therapeutic Resistance of Triple Positive Breast Cancer with CDK4/6 Inhibition. Int J Breast Cancer 2018: 7835095.

10. Canonici, Alexandra, Pedersen K, Gaynor N, Browne BC, et al. (2018) HERtargeted tyrosine kinase inhibitors enhance response to trastuzumab and pertuzumab in HER2-positive breast cancer. Invest New Drugs (2018): 1-11.

11. Ayoub, Nehad M, Kamal M Al-Shami, Rami J Yaghan (2019) Immunotherapy for HER2-positive breast cancer: recent advances and combination therapeutic approaches. Breast Cancer (Dove Med Press) 11: 53-59.

12. Corona, Silvia Paola, Ravelli A, Cretella D, Cappelletti MR, et al. (2017) CDK4/6 inhibitors in HER2-positive breast cancer. Crit Rev Oncol Hematol 112: 208-214.

13. Paplomata, Elisavet, Ruth O'Regan (2014) The PI3K/AKT/mTOR pathway in breast cancer: targets, trials and biomarkers. Ther Adv Med Oncol 6(4): 154-166.

14. Goel, Shom, Wang Q Watt AC, Tolaney SM, et al. (2016) Overcoming therapeutic resistance in HER2-positive breast cancers with CDK4/6 inhibitors. Cancer Cell 293: 255-269.

15. M Rimawi, R Cecchini, P Rastogi (2017) Abstract S3-06: A phase III trial evaluating pCR in patients with $\mathrm{HR}+$, HER2- positive breast cancer treated with neoadjuvant docetaxel, carboplatin, trastuzumab, and pertuzumab (TCHP) +/- estrogen deprivation: NRG Oncology/NSABP B-52. Cancer Research 77(4): S3-S6.

16. S Johnston, J Pippen, X Pivot (2009) Lapatinib combined with letrozole versus letrozole and placebo as frst-line therapy for postmenopausal hormone receptor-positive metastatic breast cancer. J Clin Oncol 27(33): 5538-5546.

17. B Kaufman,JR Mackey, MR Clemens (2009) Trastuzumab plus anastrozole versus anastrozole alone for the treatment of postmenopausal women with human epidermal growth factor receptor 2-positive, hormone receptor-positive metastatic breast cancer: Results from the randomized phase III TAnDEM study. J Clin Oncol 27(33): 5529-5537.

18. Gnant M, Mlineritsch B, Stoeger H, Luschin-Ebengreuth G, Knauer M, et al. (2015) Zoledronic acid combined with adjuvant endocrine therapy of tamoxifen versus anastrozol plus ovarian function suppression in premenopausal early breast cancer: final analysis of the Austrian Breast and Colorectal Cancer Study Group Trial 12. Ann Oncol 26(2): 313-320.

19. Koto K, Murata H, Kimura S, Horie N, Matsui T, et al. (2010) Zoledronic acid inhibits proliferation of human fibrosarcoma cells with induction of apoptosis, and shows combined effects with other anticancer agents. Oncol Rep 24(1): 233- 239.

20. Koto K, Murata H, Kimura S, Horie N, Matsui T, et al. (2010) Zoledronic acid inhibits proliferation of human fibrosarcoma cells with induction of apoptosis, and shows combined effects with other anticancer agents. Oncol Rep 24(1): 233- 239.

21. Di Salvatore M, Orlandi A, Bagalà C, Quirino M, Cassano A, et al. (2011) Anti-tumour and anti- angiogenetic effects of zoledronic acid on human non-small-cell lung cancer cell line. Cell Prolif 44(2): 139-146.

22. Hiraga T, Williams PJ, Ueda A, Tamura D, Yoneda T (2004) Zoledronic acid inhibits visceral metastases in the 4T1/luc mouse breast cancer model. Clin Cancer Res 10(13): 4559-4567.

23. Coscia M, Quaglino E, Iezzi M, Curcio C, Pantaleoni F, et al. (2010) Zoledronic acid repolarizes tumour- associated macrophages and inhibits mammary carcinogenesis by targeting the mevalonate pathway. J Cell Mol Med 14(12): 2803-2815.

24. Jagdev SP, Coleman RE, Shipman CM, Rostami-H A, Croucher PI (2001) The bisphosphonate, zoledronic acid, induces apoptosis of breast cancer cells: evidence for synergy with paclitaxel. Br J Cancer 84(8): 1126-1234.

25. Ottewell PD, Mönkkönen H, Jones M, Lefley DV, Coleman RE (2008) Antitumor effects of doxorubicin followed by zoledronic acid in a mouse model of breast cancer. J Natl Cancer Inst 100(16): 1167-1178.

26. (2019) Zolendronic Acid as Neoadjuvant Therapy Plus Anthracycline and Taxane in Locally Advanced Breast Cancer Available from: NLM: NCT01472146. Accessed.

27. Mejía-Pedroza, Raúl A, Jesús Espinal-Enríquez, Enrique HernándezLemus (2018) Pathway-based drug repositioning for breast cancer molecular subtypes. Front Pharmacol 9: 905.

28. Stylianou, Spyros, Rob B Clarke, Keith Brennan (2006) Aberrant activation of notch signaling in human breast cancer. Cancer Res 66(3): 1517-1525.

29. Luckman, Steven P (1998) Heterocycle-containing bisphosphonates cause apoptosis and inhibit bone resorption by preventing protein prenylation: Evidence from structure-activity relationships in J774 macrophages. J Bone Miner Res 13(11): 1668-1678.

30. Fernández-Medarde, Alberto, Eugenio Santos (2011) Ras in cancer and developmental diseases. Genes \& cancer 2(3): 344-358.

31. Alexey Goltsov, Zuzanna Kowalczyk, Rao VL (2018) Papineni Systems Biology Strategy for Drug Potentiating through Drug Repurposing: Bisphosphonates beyond Osteoporosis Treatment. J Bioanal Biomed 10(3): e154.

32. Coleman R, de Boer R, Eidtmann H, Llombart A, Davidson N, et al. (2013) Zoledronic acid (zoledronate) for postmenopausal women with early breast cancer receiving adjuvant letrozole (ZO-FAST study): final 60-month results. Ann Oncol 24(2): 398-405. 